\title{
13 \\ Data sovereignty for the Yawuru in Western Australia
}

\author{
Mandy Yap and Eunice Yư
}

\section{Introduction}

A report by the United Nations (UN) Secretary-General's Independent Expert Advisory Group on the data revolution for sustainable development suggests:

Data are the lifeblood of decision making and the raw material for accountability. Without high-quality data providing the right information on the right trend, at the right time, designing, monitoring and evaluating effective policies becomes almost impossible. (Secretary-General's IEAG 2014: 2)

This report captures the growing preoccupation with and reliance on data and indicators to guide decision-making and to design policies and programs at the international and national levels.

\footnotetext{
1 The authors would like to acknowledge that this work was undertaken on Yawuru country and extend their gratitude to the following organisations: Nyamba Buru Yawuru, Nagula Jarndu and the Yawuru Prescribed Body Corporate. We would also like to express thanks to the Centre for Aboriginal Economic Policy Research (The Australian National University) and the Kimberley Institute Limited (Broome) for in-kind and financial support given to the research. Last but not least, this chapter would not have been possible without the generous time and knowledge afforded by the Yawuru community who made the Yawuru Knowledge and Wellbeing Project come to fruition.
} 
Indigenous peoples around the world are not immune from this growing trend of quantification-based accountability (Espeland \& Vannebo 2007). There is a plethora of information pertaining to Australia's First Peoples compiled by the state and other organisations for the purposes of knowing and counting the population base for service delivery and resource allocation. Despite this, Indigenous scholars and leaders have argued that these datasets are not necessarily collected to inform the agenda and priorities of Aboriginal and Torres Strait Islander communities and organisations (Yu 2011; Walter 2013; Kukutai \& Walter 2015). Furthermore, a substantial amount of data collected within the overarching government policy framework of 'closing the gap' are narrowly defined against mainstream criteria with the objective of monitoring the extent to which Indigenous people conform to a set of predetermined characteristics of the general population. As Peter $\mathrm{Yu}$, a prominent Aboriginal leader and Yawuru man, noted in his address to the Australian Bureau of Statistics (ABS) national conference in 2011:

I contend that there is a much more fundamental flaw to the Closing the Gap Strategy. And that is that the underlying assumption is wrong. COAG [the Council of Australian Governments] is pursuing this agenda unquestioningly on the basis that Indigenous wellbeing will be improved through Indigenous people adopting values and practices of mainstream western society ... The intended use of data by governments does not measure the fundamental imperatives of Aboriginal life. (Yu 2011)

This narrow view renders other, uniquely positive, aspects of being Aboriginal or Torres Strait Islander less relevant because of their minimal contribution to the evidence base (Pholi et al. 2009). In particular, what is 'recognised' as evidence is increasingly synonymous with the creation of indicators, which are primarily quantitative in nature. These statistical indicators are commonly sourced from existing data sources collected for the purpose of informing government frameworks. The tension that exists between the world views of Indigenous peoples and government reporting frameworks is what Taylor (2008) has conceived of as existing within 'the recognition space'. The recognition space is a framework for examining the different positioning, world views and aspirations on the one side and national and international targets set by governments and international bodies on the other (Watene \& Yap 2015). 
Taylor (2008) further notes that it is in this intersectional space that meaningful engagement can begin to develop measures that reflect indigenous world views and aspirations.

Charles Taylor (1992: 25) argued for the importance of 'recognition' as a vital human need, saying that misrecognition can be seen as another form of oppression. Furthermore, the recognition of oneself and the importance of one's values and identities occurs through the interaction with others and as a product of history and institutional structures. The renegotiation and reclaiming of what is 'recognised' therefore have to occur through those same channels. One of the ways in which this space has been created is through the transformation of Western research paradigms that prioritise Indigenous ways of knowing, being and doing (Smith 1999, 2005; Martin 2003; MoretonRobinson \& Walter 2009).

In the practice of demography, Kukutai and Taylor (2013: 14) offer some insights as to how data might be 'indigenised' to better meet the needs of indigenous communities. The Yawuru people of the northwest of Western Australia (WA) have risen to this challenge: the Yawuru Knowing our Community (YKC) survey in 2011 is the first Yawuru endeavour to exercise self-determination from the ground up in their data collection efforts (Kukutai \& Taylor 2013). This chapter offers two other examples of Yawuru furthering that self-determination exercise.

\section{Data, indicators and the recognition space}

The report on the measurement of economic performance and social progress by Stiglitz et al. (2010) brought into the spotlight the inadequacies of extant measures of quality of life in terms of the need for environmental sustainability and the financial challenges that are faced globally. The statement by the authors that 'what we measure affects what we do and if our measures are flawed policies will be misguided' (Stiglitz et al. 2010: 7) astutely sums up the importance of being cognisant of what the measures represent and the unintended consequences that arise from utilising measures and indicators uncritically (Merry 2011; Fukuda-Parr 2014; see also Morphy, this volume). The report has rekindled an interest among scholars, governments and peoples around the world in interrogating how quality of life has been measured to date and how it can be better 
measured internationally as well as within different population groups and, following that, in the canvassing of indicators and associated data repositories that best reflect and capture these redefined notions of wellbeing.

At the global level, indigenous groups and organisations such as the United Nations Permanent Forum on Indigenous Issues (UNPFII) are driving a self-determination agenda to mobilise the international community to consider how to develop indicators that are culturally appropriate and reflect indigenous world views. Of particular interest is how the sustainability goals of the UN and the UN Secretary-General's Independent Expert Advisory Group (IEAG) and their various targets can incorporate and be informed by indigenous world views and aspirations for wellbeing. The themes that have been tabled include traditional knowledge and practices, health, rights, leadership, access to and control of land, self-determination and participation in matters pertaining to indigenous peoples (UNPFII 2006; PUMC-UNAM 2008).

Perhaps not surprisingly, given the breadth and depth of core themes covered, there has been a concerted effort to produce statistics and measures for indigenous populations around the world. At the very least, there is a need for better information capture and representation through disaggregation of pre-existing information by countries, by ethnicity and by gender internationally. However, a more fundamental need is to capture data that reflect indigenous aspirations and world views. This is not just information relating to indigenous peoples' social, economic and demographic circumstances, but is also information on cultural dimensions, indigenous ecological values and indigenous peoples' unique relationship to nature and the living landscape. Various scholars, many of whom are contributors to this monograph, have alluded to the fact that despite the wealth of data that national statistical agencies worldwide collect and manage, the functionality of the data in informing indigenous aspirations and world views remains questionable (Taylor 2008, 2010; Jordan et al. 2010; Prout 2011; Yu 2011; Walter \& Andersen 2013; Kukutai $\&$ Walter 2015).

In Australia, a survey of the literature, information databases and national statistics collection agencies reveals a commonality: the production of a population binary contrasting Indigenous and nonIndigenous through the inclusion of questions on self-identification 
as an Indigenous person (Walter \& Andersen 2013; Taylor 2010). For some time now, in an effort to address the weakness of postcolonial data collection frameworks, there has been a concentrated effort to produce surveys specifically designed to capture Indigenous cultural connections and social lives, such as the National Aboriginal and Torres Strait Islander Social Survey (NATSISS), the Australian Aboriginal and Torres Strait Islander Health Survey (AATSIHS) and the Longitudinal Survey of Indigenous Children (LSIC). However, these surveys do not go far enough to address the geographical and cultural diversity of the hundreds of language groups and nations that make up Australia's First Peoples, and this limits the usability of the data for informing on the wellbeing and aspirations of groups such as the Yawuru.

Clearly, there is a pressing need to improve the functionality of the current data environment for the Aboriginal and Torres Strait Islander population, but how does one begin to operationalise the recognition space so that the information reflects Indigenous aspirations and world views while simultaneously informing government planning and reporting needs? Two fundamental issues arise here: first, for what purpose are these measures or indicators being collected and represented; and second, by whom and by what process are these measures decided?

Building on Taylor's idea of the recognition space, Kukutai and Walter (2015) identify five recognition principles to address statistical functionality for indigenous peoples: geographical diversity, cultural diversity, other ways of knowing, mutual capability building and indigenous decision-making. The authors argue that these five recognition principles are the beginnings of a meaningful meeting in the recognition space, in particular for genuine participation and decision-making by indigenous peoples to shape the functionality of indigenous statistics. These principles form the building blocks of implementing the United Nations Declaration on the Rights of Indigenous Peoples (UNDRIP) in the data context.

UNDRIP, ratified in 2007, provided an international standard-setting mechanism to support indigenous peoples' right for a development paradigm that is balanced between development and sustainability; that is collective while inclusive; and, most importantly, that is reflective of and built on strength of culture and identity and is in balance and harmony with the environment. The principles of self- 
determination, participation, cultural rights, land rights, ownership, control and free prior and informed consent all form the basis for supporting indigenous groups worldwide in their efforts to set an agenda for the maintenance of their wellbeing (UN 2007).

At more localised levels, indigenous communities have begun the process of setting their own wellbeing agenda and priorities. Events set in train by the Yawuru people of Broome in WA provide a prime example of how the principles of UNDRIP can be implemented on the ground. Articles 3, 18, 19, 25, 26, 29, 31, 32 and 43 of UNDRIP were all pivotal in guiding Yawuru to develop the Knowledge and Wellbeing Project in which participation by members of the community, respect, control of information and cultural rights were central. Two case studies from this project are presented later, but first we must examine some of the background to its establishment.

\section{Native title: process and challenges}

In the seminal case of Mabo vs Queensland (No. 2) (1992), the High Court of Australia handed down its decision recognising the connection of Aboriginal and Torres Strait Islander groups to their land as passed down through their traditional laws and customs. Following that decision, the Native Title Act 1993 created the legal framework through which connection to Indigenous laws, customs and traditions is recognised to enable native title holders to deal with multiple interests on their land.

Native title brings with it significant challenges and opportunities for the native title holders. While there are potential economic benefits resulting from landholdings through native title agreements, there are significant barriers relating to property rights that need to be addressed before economic development and its benefits can be fully enjoyed. In May 2015, these challenges and issues were discussed at the high-level Indigenous Leadership Roundtable convened by the Aboriginal and Torres Strait Islander Social Justice Commissioner and the Human Rights Commissioner.

There are significant non-economic benefits arising from the recognition of native title holders, such as the pride of being recognised as traditional owners. Perhaps most important of all, 
however, native title brings with it a self-determination agenda, an opportunity to negotiate and have a say on outcomes that will affect the native title holders and, with that, an opportunity to maintain and improve their sense of wellbeing. Native title brings with it the rights and responsibilities of a seat at the table, to negotiate and manage the different competing interests on country and waters and to make decisions about what happens on their traditional land and waters (Neate 2010; Webb 2015).

Notwithstanding the difficulties of living and managing native title across two cultures and two worlds, native title determination processes act as a catalyst for thinking about data collection, data sovereignty and data usability in the context of fulfilling the rights and responsibilities that come with securing native title.

\section{Yawuru and the native title process}

Since the Bugarrigarra ${ }^{2}$ gave shape and life to the living landscape and country we now know as Broome, the Yawuru people have practised their traditions, law and customs. As custodians of the land, Yawuru have long fished and hunted in and managed their traditional ecological knowledge systems and habitats, and have held and passed their stories on to future generations despite the harsh colonisation practices instituted by the state (Dodson 2013). These stories, rituals and law handed down from the Bugarrigarra are what Yawuru women and men continued to maintain through their responsibilities and obligations as Yawuru people, which gave rise to recognition through the native title process.

2 Bugarrigarra is the core of Yawuru cosmology. Bugarrigarra is the time before time, when the creative forces shaped and gave meaning and form to the landscape, putting the languages to the people within those landscapes and creating the protocol and laws for living within this environment (Yawuru RNTBC 2011: 13). 
In 2010, the Yawuru were granted native title. ${ }^{3}$ This determination signalled a shift in the relationship between Yawuru and other groups living in Broome as well in their relationship with the state of Western Australia. The native title determination has provided Yawuru with the opportunity to have a say over the land and its use and also to have input into issues affecting Yawuru in local and regional settings (Yawuru RNTBC 2011). The native title process provided a platform for the process of knowledge building and capacity building among Yawuru. Now key players within the community, Yawuru have a significant say about and input to the growth trajectories of Broome and neighbouring areas. With that responsibility and those rights now in place, Yawuru identified the immediate need for information that will enable them to make sound decisions that will secure their economic, social, cultural and environmental base as First Peoples of Australia. There was a recognised need to, first and foremost, invest in data and knowledge development for Yawuru, driven by Yawuru, to inform Yawuru development and wellbeing aspirations. The Yawuru Knowledge and Wellbeing Project was a response to this need. It centres on four key themes: knowing Yawuru country, knowing Yawuru stories, knowing Yawuru community and building economic prosperity.

\section{Yawuru response to data needs: an exercise in self-determination}

In addressing the need to negotiate with multiple stakeholders under multiple pressures, Yawuru embarked on a project to build knowledge around their country, community and stories in an effort to 'be at the table' with information for negotiation rather than at the margins receiving information. The beginning of that knowledge project was identifying the availability and scope of data to contribute to Yawuru's knowledge base and decision-making processes (Taylor et al. 2014). Despite the wealth of data available on the Indigenous population of Australia, the usefulness of those datasets for Yawuru's purposes

3 Native title comprises the rights and interests of Indigenous Australian peoples to their traditional lands and waters, which for each group derive from their own laws and customs and are recognised by the Federal Court, in accordance with Australian statutory and common law, although subject to a judicial process of application by prospective native title holders. If determined to exist, this title is held in trust by a prescribed body corporate as per the requirements of the Native Title Act 1993. 
is limited. The Yawuru Knowing our Community (YKC) survey was Yawuru's first response to the Yawuru Knowledge and Wellbeing Project (Table 13.1).

Table 13.1 Timeline of the Yawuru native title determination and subsequent actions to implement the Knowledge and Wellbeing Project

\begin{tabular}{|l|l|}
\hline Year & Event \\
\hline 1994 & First native title claim lodged with the National Native Title Tribunal \\
\hline 2006 & $\begin{array}{l}\text { Federal Court decides that Yawuru have maintained their law } \\
\text { and customs from the time of the Bugarrigarra }\end{array}$ \\
\hline 2008 & $\begin{array}{l}\text { Appeal by the state of Western Australia against the determination } \\
\text { and finalisation of determination }\end{array}$ \\
\hline 2010 & Yawuru agreements signed \\
\hline 2011 & Yawuru Knowing our Community survey (Broome) \\
\hline 2013 & Yawuru Knowledge and Wellbeing Project commences \\
\hline
\end{tabular}

Source: The authors.

\section{Yawuru Knowledge and Wellbeing Project}

Dodson (2013) has called for a new narrative of how Indigenous people intend to assert their place in the modern world, defined by their local perspectives and reflecting values that Indigenous people (in this case, Yawuru) value and aspire to. The Yawuru Knowledge and Wellbeing Project Framework is based on Yawuru knowledge systems, ways of being and doing and the Yawuru philosophy of mabu liyan. Mabu liyan reflects the Yawuru sense of belonging and being, living well in connection with country, culture, others and oneself. In other words, liyan is relational wellbeing and concerns relationships with country, family, community and oneself (McKenna \& Anderson 2011; Dodson 2013).

Mabu buru, mabu liyan and mabu ngarrungunil are the aspirations and guiding principles of the journey that Yawuru have taken since time immemorial and they are critical for the rebuilding of the Yawuru nation in the aftermath of native title. They form the pillars of the Yawuru Knowledge and Wellbeing Project. Mabu buru refers to strong country and mabu ngarrungunil refers to strong community. Together, the interconnectedness between the country, its people and its culture brings about mabu liyan (Yawuru RNTBC 2011). 
The Yawuru demographic survey of the Broome community taken in partnership with the Kimberley Institute and The Australian National University (Table 13.1) filled the gap in 'knowing' the Broome community from the ground up (Kukutai \& Taylor 2013; Taylor et al. 2014). In the next two projects, discussed below, Indigenous ecological knowledge and Indigenous ways of knowing are critical to the foundation of a meaningful engagement in the recognition space, as a means to implement UNDRIP at the community level.

While the end product of these studies is important in itself, the methodology employed is equally significant. The innovative use of participatory methods and tools that reflect Yawuru ways of knowing, being and doing serves to challenge the existing paradigms of what matters in defining wellbeing. It takes a strength-based rather than a deficit approach and, in the case of ecological knowledge systems, paints the landscape as a living, breathing life force for transmission of knowledge, culture and the reinforcement of identity.

\section{Case study 1: Knowing our Country-mabu buru}

As traditional custodians of the land and waters in Broome, Yawuru women and men hold responsibilities arising from the Bugarrigarra to manage and protect their traditional country and waters. Traditional ecological knowledge recognises a cycle of six seasons and nine habitats, and this knowledge is part of Yawuru's spiritual relationship with the land. As with other Aboriginal groups in Australia, for Yawuru the six seasons and nine habitats are identified through weather patterns, tidal movements and the availability of traditional food sources for harvesting and hunting. Native title gave rise to the right to protect, access and live on Yawuru traditional land. It is therefore imperative for Yawuru to be informed about and consulted by any parties with interests in their land - in particular, interests and activities that have uncertain and long-lasting impacts on the land and waters in Broome. Indigenous peoples have long engaged in conceptual mapping of country, both land and sea. The biodiversity, stories, songs and history are held in their minds (Tobias 2000; Crawhall 2008). Cultural mapping has been used for some time to promote intercultural dialogue and to provide an interface where Indigenous people's knowledge and interactions with their land and sea are made visible (Crawhall 2008: 4). Working with First Nations communities in British Columbia, Terry Tobias (2000) proposed mapping as a way of documenting land 
use and occupancy by aboriginal groups. Some examples of land use and occupancy information that have been mapped include sacred sites, travel routes, aboriginal placenames, ecological knowledge, ceremonial sites and harvesting places (Tobias 2000).

Yu (2013: 26-7) states that Aboriginal groups, governments and industry need to explore ways to build workable relationships in post-native title Australia. He further notes that cultural mapping methodologies are emerging as a vital tool to assist in negotiations over and implementation of UNDRIP principles of 'free prior and informed consent'. These geospatial tools provide an interface between governments, land users and local authorities to map country so that greater transparency and accountability can be delivered to create greater social cohesion and equity between traditional societies and other citizens in their local environments and communities. Utilising Geographical Information System (GIS) mapping to digitally map places of cultural and social significance for Yawuru, alongside the Cultural Management Plan, provides Yawuru with vital information to make informed decisions about access to and use of their country to ensure its sustainability.

This mapping of Yawuru use and occupancy of country, and of important cultural and ceremony sites, is part of the compilation of vital information for Yawuru in the negotiation of land use management - in particular, around resource extraction. The information provides Yawuru with the leverage to identify potential interference with country that is not just environmental but also cultural. An example of this was highlighted in the Yawuru submission to the WA Standing Committee on Environment and Public Affairs, which stated:

Yawuru considers water sites on country to be 'living waters' which are permanent springs and manifestations of the Bugarrigarra. Many water sites are inhabited by powerful snake-like spiritual beings. Contaminated waters as a result of fracking would impact upon the sustainability and cultural integrity of water sites and therefore impinge on Yawuru's fundamental native title rights and responsibility to look after country. (Yawuru RNTBC 2013: 6) 
The maps generated through Yawuru's Knowing our Country efforts have been critical in casting a spotlight on their significant cultural and hunting sites and use of country to inform negotiation and management processes with various government departments and stakeholders in the region (Rangelands NRM 2016).

\section{Case study 2: Knowing our Community-mabu liyan}

Following on from the native title determination, there has been a need to pause to reflect on whether the programs and policies in place are improving the lives of Yawuru men and women. Conceptions of wellbeing cannot be meaningfully disentangled from place, time and history. To investigate whether the wellbeing of Yawuru women and men is being maintained and improving, there is a need to first understand how Yawuru conceptualise wellbeing and to understand what social, cultural and economic aspects they most value.

The Yawuru Knowledge and Wellbeing Project is a sequential mixedmethods project aimed at understanding Yawuru conceptions of and priorities for wellbeing. For the most part, measures of wellbeing are often sourced from existing surveys with limited functionality in representing community-level wellbeing (Taylor 2008; Yu 2011). Furthermore, where composite measures of wellbeing are created, the weights attached to the various dimensions of wellbeing tend to be determined by the researchers, either as equally important or through using statistical weights (Biddle 2009; Yap \& Biddle 2010).

In this project, Yawuru ways of being, knowing and doing are prioritised in several ways: first, through the framing of Yawuru wellbeing through the philosophy of mabu liyan, and second, in the participatory way in which measures of wellbeing were derived, validated, collected and weighted.

Mabu liyan is a central notion of wellbeing for Yawuru. Pursuits of various aspects of wellbeing identified by Yawuru women and men were often associated with achieving and maintaining mabu liyan or 'good' liyan. Starting with mabu liyan as the central focus of Yawuru wellbeing is recognising that there are other ways of 'knowing'. This means that the wellbeing measures are grounded in Yawuru values through a process that results in data that are fit for purpose. 
This is done with the aim of evaluating how Yawuru women and men are faring over time against their own determined benchmarks (see Morphy, this volume).

The participation and guidance of Yawuru women and men through all stages of the research process, from content and design to collection, are the second way in which Yawuru voices are prioritised. This bottomup approach for conceptualising wellbeing, selecting wellbeing dimensions and the weighting of wellbeing ensures that if Yawuru set out on the road to constructing a Yawuru wellbeing index, as suggested by $\mathrm{Yu}(2011)$ in his address at the ABS conference, the index in its entirety will be grounded in Yawuru world views, reflecting Yawuru priorities, with Yawuru voices and inputs interwoven throughout the process. A further way in which the Yawuru's critical voice has been prioritised in the conceptualisations of wellbeing and liyan is through the formation of a steering committee consisting of Yawuru women and men to ensure that the information generated through the research reflects local aspirations and values but, more importantly, is functional for community purposes.

There were two broad stages to the research, with the qualitative component informing the quantitative instrument of the Yawuru Wellbeing Survey 2015. The first stage comprised two interconnected phases involving face-to-face semistructured interviews and focus group workshops with Yawuru women and men to conceptualise ideas of a good life. Together, the interviews and focus groups formed the Yawuru Wellbeing Framework (for women and men separately) and the Yawuru Wellbeing Survey, which was conducted in the quantitative stage (Yap \& Yu, in press). The construction of a genderspecific Yawuru Wellbeing Framework, reflecting the different but overlapping priorities and concerns of Yawuru women and men, is an innovative contribution to this process. The grounding of the process in Yawuru world views not only facilitated the derivation of culturally relevant measures, but also created a sense of 'ownership' in the operation of the recognition space (Table 13.2). 
Table 13.2 Examples of grounded community-driven approaches for deriving measures of wellbeing

\begin{tabular}{|l|l|l|l|l|}
\hline Themes & $\begin{array}{l}\text { Examples of } \\
\text { interview }\end{array}$ & Indicators & $\begin{array}{l}\text { Selected/not } \\
\text { selected by } \\
\text { focus groups }\end{array}$ & $\begin{array}{l}\text { Survey } \\
\text { question }\end{array}$ \\
\hline $\begin{array}{l}\text { Connection } \\
\text { to country }\end{array}$ & $\begin{array}{l}\text { I try and get back } \\
\text { into country in the } \\
\text { afternoons. I go back } \\
\text { and I sit down on } \\
\text { the rocks, get out on } \\
\text { country and go fishing } \\
\text { and that makes my } \\
\text { liyan feel good' }\end{array}$ & $\begin{array}{l}\text { Fishing and } \\
\text { hunting }\end{array}$ & $\begin{array}{l}\text { Picked by } \\
\text { Yawuru women } \\
\text { Picked by } \\
\text { Yawuru men }\end{array}$ & $\begin{array}{l}\text { In the past } \\
12 \text { months, } \\
\text { how often did } \\
\text { you fish or } \\
\text { hunt? }\end{array}$ \\
\hline $\begin{array}{l}\text { 'Yawuru use[d] to get } \\
\text { blood cockle ... we } \\
\text { are saltwater people } \\
\text { and we hunt from } \\
\text { the sea. The cockles } \\
\text { have disappeared } \\
\text { now. People feel very } \\
\text { low from a wellbeing } \\
\text { perspective that this } \\
\text { cockle has gone ... } \\
\text { our liyan no good } \\
\text { when we see that' }\end{array}$ & $\begin{array}{l}\text { Quality and } \\
\text { quantity of }\end{array}$ & $\begin{array}{l}\text { Picked by } \\
\text { Yawuru women kill } \\
\text { Picked by } \\
\text { Yawuru men }\end{array}$ & $\begin{array}{l}\text { In the past } \\
\text { did you eat } \\
\text { traditional food } \\
\text { (catch, kill or } \\
\text { bushfood)? }\end{array}$ \\
\hline
\end{tabular}

Source: Adapted from Yap and Yu (in press).

\section{Summary and discussion}

It is clear from the case studies provided that the guiding principles around the Yawuru Knowledge and Wellbeing Project are not dissimilar to the spirit and values underpinning UNDRIP. Both emphasise the importance of geographical and cultural context, and of empowering communities to fashion their own development agendas and solutions.

The projects are also strength based, stemming from Yawuru aspirations and the values that underpin knowing our country, knowing our stories and knowing our community. Together, these key pillars can bring about healthy country, strong community and mabu liyan in parallel with the pursuit of economic development. The importance of building and recognising Yawuru ways of knowing and being is a key foundation of the meaningful operation of Taylor's recognition space through the key recognition principles outlined by Kukutai and Walter (2015). 
The exercise of self-determination through active and meaningful participation by members of the community in both of the projects discussed above is crucial to building an evidence base that is relevant but reflective of the diversity and lived experiences of different members of the community: women and men, young and old, those living on country and those living away from country. This is important in the endeavour of being inclusive and transparent while moving ahead as a collective.

Last but not least, the capacity-building component of both research projects through research partnerships with universities, community organisations such as Kimberley Institute and the prescribed bodies corporate, and the training of a local research team, ensures that there is co-production of knowledge. This brings together different ways of knowing, both traditional and Western, in a manner that is more consistent with the recognition space.

There are, however, challenges associated with operationalising the recognition space. The investment required in both time and resources is extensive and there is a need to ensure enduring consistency and comparability over time. Evaluation of wellbeing and priorities needs to be undertaken periodically - especially in a time when there are environmental and economic pressures that need to be balanced against social and cultural considerations, with sometimes very short time frames for decision-making.

As the reality of native title sets in, the information gathered to inform Yawuru priorities acts as a compass showing where Yawuru are and where they are heading. A key to the implementation of self-determination is ensuring that the utility of Yawuru data is communicated so that such projects are always accountable to the native title holders, the community, and the elders and senior lawmen whose efforts and stories gave rise to the recognition of Yawuru as traditional custodians of Broome, long before European contact. Their stories, their investment of time and their knowledge serve to populate the data collection instruments that Yawuru have initiated and, ultimately, they are the ones who will benefit from the fruits of these processes and the data and information that they produce. 


\section{References}

Biddle N (2009). Ranking regions: revisiting an index of relative indigenous socioeconomic outcomes, CAEPR Working Paper 50, Centre for Aboriginal Economic Policy Research, The Australian National University, Canberra, anu.edu.au/caepr/working.php.

Crawhall $\mathrm{N}$ (2008). The role of participatory cultural mapping in promoting intercultural dialogue: 'we are not hyenas', Concept Paper prepared for Division of Cultural Policies and Intercultural Dialogue, February 2007, United Nations Educational, Scientific and Cultural Organization, Paris.

Dodson P (2013). Doctrine I: an Indigenous doctrine of discovery post terra nullius, Presentation to Thinking for yourself: a conference in honour of Robert Manne, La Trobe University, Melbourne, 28 February 2013.

Espeland W \& Vannebo B (2007). Accountability, quantification and law. Annual Review of Law and Social Science 3:21-43.

Fukuda-Parr S (2014). Global goals as a policy tool: intended and unintended consequences. Journal of Human Development and Capabilities 15(2-3):118-31, doi:10.1080/19452829.2014.91018.

Jordan K, Bullock H \& Buchanan G (2010). Exploring the tensions between statistical equality and cultural difference in Indigenous wellbeing frameworks: a new expression of an enduring debate. Australian Journal of Social Issues 45(3):333-62.

Kukutai T \& Taylor J (2013). Postcolonial profiling of indigenous populations: limitations and responses in Australia and New Zealand. Espace Populations Sociétés 1:13-27.

Kukutai T \& Walter M (2015). Recognition and indigenizing official statistics: reflections from Aotearoa New Zealand and Australia. Statistical Journal of the IAOS 31:317-26.

McKenna V \& Anderson K (2011). Kimberley Dreaming: old law, new ways - finding new meaning, Presentation to World Congress for Psychotherapy, Sydney, 24-28 August 2011. 
Martin K (2003). Ways of knowing, ways of being and ways of doing: a theoretical framework and methods for Indigenous research and Indigenist research. Journal of Australian Studies 76:203-14.

Merry S (2011). Measuring the world indicators, human rights, and global governance. Current Anthropology 52(S3):s83-95.

Moreton-Robinson AM \& Walter M (2009). Indigenous methodologies in social research. In Walter $\mathrm{M}$ (ed.), Social research methods: an Australian perspective, 2nd edn, Oxford University Press, Melbourne.

Neate G (2010). Using native title to increase Indigenous economic opportunities, Presentation to fifth Indigenous Recruitment and Training Summit, Brisbane, 6 December 2010.

Pholi K, Black D \& Richards C (2009). Is 'Close the Gap' a useful approach to improving the health and wellbeing of Indigenous Australians? Australian Review of Public Affairs 9(2):1-13.

Prout S (2011). Indigenous wellbeing frameworks in Australia and the quest for quantification. Social Indicators Research 109(2):317-36.

Rangelands NRM (2016). GIS plan highlights diverse values of Roebuck Plains, Rangelands NRM WA, Perth, rangelandswa.com.au/856/ gis-plan-highlights-diverse-values-of-roebuck-plains-.

Secretary-General's Independent Expert Advisory Group (IEAG) (2014). A world that counts: mobilising the data revolution for sustainable development, United Nations, New York.

Smith LT (1999). Decolonising methodologies: research and indigenous peoples, Zed Books, London \& New York.

Smith LT (2005). On tricky ground: researching the native in the age of uncertainty. In Denzin NK \& Lincoln YS (eds), The SAGE handbook of qualitative research, 3rd edn, SAGE Publications, Thousand Oaks, CA.

Stiglitz J, Sen A \& Fitoussi J (2010). Report by the Commission on the Measurement of Economic Performance and Social Progress, Paris. 
Taylor C (1992). The politics of recognition. In Guttmann A \& Taylor C (eds), Multiculturalism and the 'politics of recognition', Princeton University Press, Princeton, NJ.

Taylor J (2008). Indigenous peoples and indicators of well-being: Australian perspectives on United Nations global frameworks. Social Indicators Research 87(1):111-26.

Taylor J (2010). Postcolonial transformation of the Australian Indigenous population. Geographical Research 49(3):286-300.

Taylor J, Doran B, Parriman M \& Yu E (2014). Statistics for community governance: the Yawuru Indigenous population survey, Western Australia. International Indigenous Policy Journal 5(2):1-31.

Tobias T (2000). Chief Kerry's moose: a guidebook to land use and occupancy mapping, research design and data collection, Union of British Columbia Indian Chiefs and Ecotrust Canada, Vancouver.

United Nations (UN) (2007). United Nations declaration on the rights of indigenous peoples, General Assembly Resolution 61/295, 13 September 2007, United Nations, New York, www.un.org/esa/ socdev/unpfii/documents/DRIPS_en.pdf.

United Nations Permanent Forum on Indigenous Issues (UNPFII) (2006). Report on the meeting on indigenous peoples and indicators of wellbeing, United Nations Permanent Forum on Indigenous Issues, Fifth Session, New York.

Walter M (2013). The 2014 National Aboriginal and Torres Strait Islander Social Survey is an anachronism, Online Opinion, 6 August 2013, onlineopinion.com.au/view.asp?article $=15317$.

Walter M \& Andersen C (2013). Indigenous statistics: a quantitative research methodology, Left Coast Press, Walnut Creek, CA.

Watene K \& Yap M (2015). Culture and sustainable development: indigenous contributions. Journal of Global Ethics 11:51-5.

Webb R (2015). Historic Tenure Certainty Project: a tool for sharing the knowledge, sharing the future, Paper presented at the 2015 World Bank Conference on Land and Poverty, Washington, DC, 23-27 March 2015. 
Working Group Mexico Multicultural Nation University Programme and the National Autonomous University of Mexico (PUMCUNAM) (2008). Indigenous peoples and the indicators of well-being and development, Preliminary Report, Seventh Session of the United Nations Permanent Forum on Indigenous Issues, New York.

Yap M \& Biddle N (2010). Gender gaps in Indigenous socioeconomic outcomes: Australian regional comparisons and international possibilities. International Indigenous Policy Journal 1(2).

Yap M \& Yu E (in press). Operationalising the capability approach: developing culturally relevant indicators of Indigenous wellbeingan Australian example. Oxford Development Studies.

Yawuru Native Title Holders Aboriginal Corporation Native Title Prescribed Body Corporate (Yawuru RNTBC) (2011). Walyjala-jala buru jayida jarringgun Nyamba Yawuru ngan-ga mirlimirli: planning for the future - Yawuru cultural management plan, Pindan Printing, Broome, WA.

Yawuru Native Title Holders Aboriginal Corporation Native Title Prescribed Body Corporate (Yawuru RNTBC) (2013). Submission to the Standing Committee on Environment and Public Affairs: inquiry into the implications for Western Australia of hydraulic fracturing for unconventional gas, September 2013, Perth.

Yu P (2011). Aboriginal development: making data work, Paper presented at the ABS Conference Census: beyond the count, Melbourne, 3 March 2011.

Yu P (2013). Process from the other side: liyan in the cultural and natural estate. Landscape Architecture Australia 139(August). 
This text is taken from Indigenous Data Sovereignty: Toward an agenda, edited by Tahu Kukutai and John Taylor, published 2016 by ANU Press, The Australian National University, Canberra, Australia. 